\title{
ANALISIS PEMANFAATAN KOLEKSI AMERICAN CORNER DI PERPUSTAKAAN UNAND
}

\author{
Gema Putra Islami ${ }^{1}$ \& Habiburrahman \\ ${ }^{1}$ Universitas Negri Padang \\ ${ }^{2}$ Universitas Negri Padang \\ Correspondence email: emaputra0799@gmail.com
}

\begin{abstract}
Collection is a term that is used widely in the library world to describe what library materials should be held in the library. Types of library collections, printed collections, non-printed collections, graphic material collections, electronic collections. American Corner is one of the services in collaboration with the Unand library. There are 4 corner services at the Unand library, namely American Corner, Franch Corner, Minangkabau Corner and BI Corner. American Corner itself is a service under the American embassy in Indonesia which aims to introduce, attract and broaden Unand students' knowledge about all things about America. The method used is qualitative, namely in the form of direct interviews with related parties. After the data has been collected, the writer will analyze the results of the interview and make a way for how the use of this collection can be used by all Unand students.
\end{abstract}

Keywords: American Corner, Collections, Media

\begin{abstract}
Abstrak
Koleksi adalah suatu istilah yang digunakan secara luas di dunia perpustakaan untuk menyatakan bahan perpustakaan apa saja yang harus diadakan di perpustakaan. Jenis koleksi perpustakaan, koleksi tercetak, koleksi non cetak, koleksi bahan grafika, koleksi dalam bentuk elektronik American Corner merupakan salah satu layanan yang bekerjasama dengan perpustakaan Unand. Layanan corner di perpustakaan Unand sendiri memiliki
\end{abstract}


4 yaitu American Corner, Franch Corner, Minangkabau Corner dan BI Corner. American Corner sendiri merupakan layanan di bawah lembaga kedutaan Amerika yang ada di Indonesia yang bertujuan memperkenalkan, serta menarik minat dan menambah wawasan mahasiswa Unand tentang segala hal tentang Amerika. Metode yang dipakai ialah kualitatif yaitu berupa wawancara langsung terhadap pihak yang terkait. Setelah data terkumpul maka penulis akan menganalisis hasil dari wawancara dan melakukan cara untuk bagaimana pemanfaatan koleksi ini dapat dimanfaatkan oleh seluruh mahasiswa Unand.

Kata kunci: American Corner, Koleksi, Media 


\section{A. Pendahuluan}

Perpustakaan merupakan sebuah koleksi buku dan majalah bisa sebagai tempat pribadi perseorangan, namun perpustakaan lebih umum dikenal sebagai sebuah koleksi besar yang dibiayai dan dioperasikan oleh sebuah kota atau institusi, serta dimanfaatkan oleh masyarakat yang rata-rata tidak mampu membeli sekian banyak buku dengan biaya sendiri. Tetapi, dengan koleksi dan penemuan media baru selain buku untuk menyimpan informasi, banyak perpustakaan kini juga merupakan tempat penyimpanan dan/atau akses ke map, cetak atau hasil seni lainnya, mikrofilm, mikrofiche, tape audio, CD, LP, tape video dan DVD. Selain itu, perpustakaan juga menyediakan fasilitas umum untuk mengakses gudang data CDROM dan internet. Oleh karena itu saat ini banyak perpustakaan modern yang tidak berdiri sendiri melainkan banyak bekerjasama dengan pihak lain agar dapat membantu perpustakaan dalam menambah koleksinya dengan jenis yang beragam begitu juga dengan lembaga yang bekerjasama dengan perpus mereka juga mendapatkan feedback seperti iklan atau pengenalan di sebuah perpustakaan agar masyarakat atau pemustaka mengetahui lembaga tersebut. (Helsa, 2014)

Banyak sekali lembaga-lembaga yang bekerjasama dengan perpustakaan salah satunya adalah American Corner. Lembaga ini merupakan salah satu lembaga di bawah naungan kedutaan besar Amerika. Salah satu dari tujuan lembaga ini untuk bekerjasama dengan perpustakaan dimana yaitu untuk mengenalkan tentang budaya, bahasa, serta apa saja tentang Amerika yang mana targetnya yaitu pemustaka dan masyarakat yang datang dan berkunjung ke perpustakaan tersebut. Salah satu perpustakaan yang bekerjasama dengan layanan American Corner ini adalah perpustakaan pusat Unand yang terletak di kampus utama Limau Manih. Menurut Ade Kohar (2003 : 6), "Koleksi perpustakaan adalah yang mencakup berbagai format bahan sesuai dengan perkembangan dan kebutuhan alternatif para pemakai perpustakaan terhadap media rekam informasi”. (Helsa, 2014) 
Jenis koleksi perpustakaan menurut Yulia (1993 : 3) ada empat jenis koleksi perpustakaan yaitu:

1. Karya cetak

2. Karya non cetak

3. Bahan grafika

4. Karya dalam bentuk elektronik (Helsa, 2014)

Tujuan dari penelitian ini adalah sebagai bahan pengetahuan penelitian selanjutnya serta sebagai evaluasi dan solusi agar koleksi di layanan American Corner bisa dimanfaatkan secara maksimal oleh mahasiswa dan pemustaka lainnya yang ada di perpustakaan Unand.

\section{B. Metodologi Penelitian}

Penelitian ini menggunakan penelitian kualitatif. Menurut Crosswell metode penelitian kualitatif menuntut peneliti untuk mengambil kesimpulan dari hasil pandangan yang diperoleh dari para partisipan. Pengumpulan data dilakukan melalui observasi, wawancara, dan dokumentasi. Instrumen penelitian meliputi peneliti sendiri, pendoman wawancara, dan catatan lapangan. Teknik penentuan informan menggunakan purposive sampling. Teknik analisis data meliputi menurut Sugiyono ada tiga, yaitu : reduksi data, penyajian data, verification/kesimpulan. (Moprita, 2017)

\section{Hasil Penelitian}

\section{Koleksi Perpustakaan}

Koleksi adalah suatu istilah yang digunakan secara luas di dunia perpustakaan untuk menyatakan bahan perpustakaan apa saja yang harus diadakan di perpustakaan. Sebelumnya muncul istilah seleksi buku, buku dalam pengertian yang lebih luas yang mencakup monografi, majalah, bahan mikro dan jenis bahan perpustakaan lainnya. Menurut ALA Glossary of Library and Information Science (1983) pengembangan koleksi merupakan sejumlah kegiatan yang berkaitan dengan 
penentuan dan koordinasi kebijakan seleksi, menilai kebutuhan pemakai, studi pemakaian koleksi, evaluasi koleksi, identifikasi kebutuhan koleksi, seleksi bahan pustaka, perencanaan kerjasama sumberdaya koleksi, pemeliharaan koleksi dan penyiangan koleksi perpustakaan. Sedangkan menurut Ade Kohar (2003 : 6), "Koleksi perpustakaan adalah yang mencakup berbagai format bahan sesuai dengan perkembangan dan kebutuhan alternatif para pemakai perpustakaan terhadap media rekam informasi". Jadi dapat disimpulkan bahwa koleksi perpustakaan adalah semua kebutuhan yang ada di perpustakaan yang dapat perlukan oleh pengguna atau pemustaka di perpustakaan tersebut. (Helsa, 2014)

Koleksi di perpustakaan memiliki beberapa jenis yang dapat dibedakan menurut Yulia (1993 : 3) ada empat jenis koleksi perpustakaan yaitu :

1. Karya cetak

2. Karya noncetak

3. Bahan grafika

4. Karya dalam bentuk elektronik (Helsa, 2014)

\section{Layanan American Corner}

American Corner merupakan salah satu lembaga yang bekerjasama dengan perpustakaan, salah satu perpustakaan yang bekerjasama dengan lembaga American Corner yaitu perpustakaan perguruan tinggi Unand, perpustakaan ini bekerjasama dengan American Corner yang bertujuan untuk memenuhi kebutuhan informasi untuk mahasiswanya dan pemustaka lainnya. Untuk layanan yang ada di American Corner sendiri terdapat beberapa layanan yaitu , layanan volunteer, layanan koleksi, layanan kegiatan dan acara, dan layanan multimedia. Layana American Corner sendiri merupakan bentuk kerjasama perpustakaan Unand dengan kedutaan besar Amerika yang mana American Corner sendiri bertujuan untuk mengenalkan budaya, bahasa, ekonomi, sejarah dan geografis serta hal yang menyangkut dengan Amerika. 
Dengan begitu mahasiswa dapat tertarik dan mempelajari tentang hal yang ada di Amerika disana serta bentuk media promosi untuk mengikat hati para mahasiswa yang bertujuan untuk melanjutkan studinya salah satunya ke negeri Paman Sam ini. (Moprita, 2017)

\section{Pembahasan}

\section{Koleksi Bahan Pustaka}

Koleksi adalah suatu istilah yang digunakan secara luas di dunia perpustakaan untuk menyatakan bahan perpustakaan apa saja yang harus diadakan di perpustakaan. Sebelumnya muncul istilah seleksi buku, buku dalam pengertian yang lebih luas yang mencakup monografi, majalah, bahan mikro dan jenis bahan perpustakaan lainnya. Menurut ALA Glossary of Library and Information Science (1983) pengembangan koleksi merupakan sejumlah kegiatan yang berkaitan dengan penentuan dan koordinasi kebijakan seleksi, menilai kebutuhan pemakai, studi pemakaian koleksi, evaluasi koleksi, identifikasi kebutuhan koleksi, seleksi bahan pustaka, perencanaan kerjasama sumberdaya koleksi, pemeliharaan koleksi dan penyiangan koleksi perpustakaan. Sedangkan menurut Ade Kohar (2003 : 6), "Koleksi perpustakaan adalah yang mencakup berbagai format bahan sesuai dengan perkembangan dan kebutuhan alternatif para pemakai perpustakaan terhadap media rekam informasi". Jadi dapat disimpulkan bahwa koleksi perpustakaan adalah semua kebutuhan yang ada di perpustakaan yang dapat perlukan oleh pengguna atau pemustaka di perpustakaan tersebut. (Helsa, 2014)

Bahan pustaka adalah bagian dari koleksi perpustakaan yang ada di perpustakaan dalam arti lain, bahan pustaka adalah salah satu koleksi perpustakaan yang berupa karya cetak seperti buku pengunjung, buku fisik, dan referensi yang diolah dan disimpan untuk disajikan kepada pengguna untuk memenuhi kebutuhan informasi.

\section{Jenis Koleksi Perpustakaan}

Jenis koleksi perpustakaan dapat dibagi menjadi 4 menurut Yulia (1993 : 3) yaitu: 
a. Karya cetak

Karya cetak adalah hasil pemikiran manusia yang dituangkan dalam bentuk cetak, seperti :

1) Buku

Buku adalah bahan pustaka yang merupakan suatu kesatuan utuh dan yang paling utama terdapat dalam koleksi perpustakaan. Berdasarkan standar dari UNESCO, tebal buku paling sedikit 49 halaman tidak termasuk kulit maupun jaket buku. Di antaranya buku fiksi, buku teks, dan buku rujukan.

2) Terbitan berseri

Bahan pustaka yang direncanakan untuk diterbitkan terus dengan jangka waktu terbit tertentu. Yang termasuk dalam bahan pustaka ini adalah harian (surat kabar), majalah (mingguan bulanan dan lainnya), laporan yang terbit dalam jangka waktu tertentu, seperti laporan tahunan, tri wulanan, dan sebagainya.

b. Karya noncetak

Karya noncetak adalah hasil pemikiran manusia yang dituangkan tidak dalam bentuk cetak seperti buku atau majalah, melainkan dalam bentuk lain seperti rekaman suara, rekaman video, rekaman gambar dan sebagainya. Istilah lain yang dipakai untuk bahan pustaka acheter viagra ini adalah bahan non buku, ataupun bahan pandang dengar. Yang termasuk dalam jenis bahan pustaka ini adalah:

\section{1) Rekaman suara}

Yaitu bahan pustaka dalam bentuk pita kaset dan piringan hitam. Sebagai contoh untuk koleksi perpustakaan adalah buku pelajaran bahasa Inggris yang dikombinasikan dengan pita kaset.

2) Gambar hidup dan rekaman video 
Yang termasuk dalam bentuk ini adalah film dan kaset video. Kegunaannya selain bersifat rekreasi juga dipakai untuk pendidikan. Misalnya untuk pendidikan pemakai, dalam hal ini bagimana cara menggunakan perpustakaan.

c. Bahan Grafika

Ada dua tipe bahan grafika yaitu bahan pustaka yang dapat dilihat langsung (misalnya lukisan, bagan, foto, gambar, teknik dan sebagainya) dan yang harus dilihat dengan bantuan alat (misalnya selid, transparansi, dan filmstrip).

1) Bahan kartografi yang termasuk kedalam jenis ini adalah peta, atlas, bola dunia, foto udara, dan sebagainya.

2) Bentuk mikro adalah suatu istilah yang digunakan untuk menunjukkan semua bahan pustaka yang menggunakan media film dan tidak dapat dibaca dengan mata biasa melainkan harus memakai alat yang dinamakan microreader. Bahan pustaka ini digolongkan tersendiri, tidak dimasukkan bahan noncetak.

d. Karya dalam bentuk elektronik

Dengan adanya teknologi informasi, maka infornasi dapat dituangkan ke dalam media elektronik seperti pita magnetis dan cakram atau disc. Untuk membacanya diperlukan perangkat keras seperti computer, CD-ROM player, dan sebagainya. (Helsa, 2014)

\section{Pengembangan Koleksi}

Pengembangan koleksi merupakan salah satu sarana dalam suatu perpustakaan perguruan tinggi, menurut Ade Kohar (2003 : 6), "Pengembangan koleksi adalah sejumlah kegiatan yang berkaitan dengan penentuan dan koordinasi kebijakan seleksi, menilai kebutuhan pemakai, studi pemakaian koleksi, evaluasi koleksi, 
identifikasi kebutuhan koleksi, seleksi bahan pustaka, perencanaan kerjasama sumberdaya koleksi, pemeliharaan koleksi, dan penyiangan koleksi perpustakaan”

\section{a. Tujuan Pengembangan Koleksi}

Tujuan pengembangan koleksi di perpustakaan sendiri untuk memenuhi permintaan dan kebutuhan pemustaka terhadap bahan bacaan dan informasi yang dibutuhkan oleh pemustaka. menurut Sutarno NS (2006 :115), "Pengembangan koleksi bertujuan untuk menambah jumlah koleksi, meningkatkan dan jenis bahan bacaan, dan meningkatkan mutu koleksi sesuai dengan kebutuhan masyarakat pemakai". Dapat disimpulkan bahwa pengembangan koleksi yang baik dan yang benar dengan mempertimbangkan permintaan dan kebutuhan pengguna dengan disusun melalui standar perpustakaan sehingga dapat memenuhi kebutuhan informasi pemustaka.

b. Manfaat Pengembangan Koleksi

Menurut Sutarno NS (2006 : 118), manfaat pengembangan koleksi antara lain :

1) Membantu menetapkan metode untuk menilai bahan pustaka yang harus dibeli.

2) Membantu merencanakan bentuk-bentuk kerja sama dengan perpustakaan lain, seperti pinjam antar perpustakaan, kerjasama dalam pengadaan, dan sebagainya.

3) Membantu identifikasi bahan pustaka yang perlu dipindahkan ke gudang atau dikeluarkan dari koleksi.

4) Membantu dalam merencanakan anggaran jangka panjang dengan menetapkan prioritas-prioritas dan garis besar sasaran pengembangan.

5) Membantu memilih cara terbaik untuk pengadaan.

c. Kegiatan Pengembangan Koleksi 
1) Menentukan kebijakan umum pengembangan koleksi berdasarkan identifikasi kebutuhan pengguna sesuai dengan asas tersebut di atas. Kebijakan ini disusun bersama oleh sebuah tim yang dibentuk dengan keputusan rektor dan anggotanya terdiri atas uns perpustakaan, fakultas atau jurusan, dan unit lain.

2) Menentukan kewenangan, tugas, dan tanggung jawab semua unsur yang terlibat dalam pengembangan koleksi.

3) Mengidentifikasi kebutuhan akan informasi dari semua anggota sivitas akademika yang dilayani. (Helsa, 2014)

\section{Layanan American Corner}

Perpustakaan Unand adalah salah satu perpustakaan yang menjalin kerjasama dengan lembaga American Corner, layanan ini sendiri pertama kali diresmikan pada tanggal 6 Maret 2014, American Corner yang bertujuan untuk memenuhi kebutuhan informasi untuk mahasiswanya dan pemustaka lainnya. Untuk layanan yang ada di American Corner sendiri terdapat beberapa layanan yaitu , layanan volunteer, layanan koleksi, layanan kegiatan dan acara, dan layanan multimedia. Layanan American Corner sendiri merupakan bentuk kerjasama perpustakaan Unand dengan kedutaan besar Amerika yang mana American Corner sendiri bertujuan untuk mengenalkan budaya, bahasa, ekonomi, sejarah dan geografis serta hal yang menyangkut dengan Amerika. Dengan begitu mahasiswa dapat tertarik dan mempelajari tentang hal yang ada di Amerika disana serta bentuk media promosi untuk mengikat hati para mahasiswa yang bertujuan untuk melanjutkan studinya salah satunya ke negeri Paman Sam ini. (Sari, 2016)

Koleksi yang terdapat pada layanan American Corner berbentuk tercetak dan elektronik, untuk koleksi tercetak yang disediakan oleh layanan American Corner di antaranya adalah :

a. Koleksi cetak terdiri dari referensi dan buku-buku di bidang karya fiksi, bisnis, ilmu sosial, politik, pendidikan dan kebudayaan;

b. Majalah, jurnal, laporan dan koran; 
c. Jurnal yang diterbitkan oleh Biro Informasi Internasional pemerintah Amerika. (Sari, 2016)

Sedangkan koleksi elektronik yang terdapat pada layanan American Corner di antaranya adalah:

a. Akses ke multimedia: produk video dan audioseperti CD dan DVD koleksi musik dan film, serta CD-ROM untuk sumber informasi;

b. Jurnal elektronik Information Resource Center (IRC);

c. Situs Amerika yang berada dalam bidang penelitian sebagai sumber informasi.

Fasilitas yang tersedia pada layanan American Corner yang digunakan untuk menunjang keefektivitasan pengguna diantaranya adalah:
a. Sofa;
b. Meja diskusi;
c. Ruangan kedap suara full AC;
d. Komputer dengan jaringan internet sebanyak sembilan buah;
e. Rak lemari;
f. Ruangan teater beserta DVD dan TV LCD;
g. Media untuk permainan atau games;
h. Loker, tempat penitipan barang pengunjung;
i. Dan mesin fotokopi (Sari, 2016)

Untuk data pengunjung sendiri penulis tidak dapat menyimpulkan berapa data pengunjung untuk setiap harinya dikarnakan adanya pandemi Covid 19 ini sehingga mahasiswa dirumahkan sehingga untuk pengunjung sendiri yang penulis lihat tidak ada, tetapi penulis mendapatkan data dan informasi berdasarkan tugas akhir dari Elviza Agustina Sari dimana ia menuliskan data pengunjung berkisar antara 50 sampai 80 orang mahasiswanya setiap hari, dan menurut penulis data tersebut tidak akan jauh berbeda jika masa pandemic ini tidak ada. 


\section{E. Daftar Pustaka}

Andi Setiawan, R. A. (2019). Layanan Pojok Braille dalam Meningkatkan Literasi Baca bagi Disabilitas Netra di Kota Malang. Jurnal Transformative.

Helsa. (2014). Koleksi Perpustakaan. Jurnal Pendidikan.

Moprita. (2017). Pemanfaatan Layanan American Corner di Perpustakaan Universitas Andalas. Repository Usu.

Nduet, F. (2019). Pelaksanaan Inovasi Layanan Pojok Braille (Lapo Bra) dalam Meningkatkan Pelayanan Publik (Studi pada Dinas Perpustakaan Umum dan Arsip Daerah Kota Malang. Jurnal Ilmu Sosial dan Politik.

Sari, E. A. (2016). Layanan Korner di Perpustakaan Universitas Andalas. Jurnal Ilmu Informasi Perpustakaan dan Kearsipan. 